\title{
THE LUNG VOLUME AND ITS SUBDIVISIONS IN THE UPRIGHT AND RECUMBENT POSITIONS IN PATIENTS WITH CON- GESTIVE FAILURE. PULMONARY FACTORS IN THE GENESIS OF ORTHOPNEA
}

\author{
By M. D. ALTSCHULE, N. ZAMCHECK, AND A. IGLAUER \\ (From the Medical Service and Medical Research Laboratories, Beth Israel Hospital, \\ and the Department of Medicine, Harvard Medical School, Boston)
}

(Received for publication February 17, 1943)

\section{INTRODUCTION}

Orthopnea is a common complaint in patients with chronic cardiac decompensation. The frequent association of orthopnea and pulmonary congestion has properly led many authors to regard congestion of the lungs as an important factor in the genesis of dyspnea in the recumbent position, the symptom being favorably modified in the upright position. There has, however, been no general agreement regarding the mechanism whereby pulmonary congestion induces or exaggerates dyspnea in recumbency. A number of authors have stated that dyspnea of recumbency results from increased pulmonary congestion in the recumbent position, consequent to a shift of blood from the lower part of the body (1), pressure on (2) or unfavorably hydrostatic relations within (3) the pulmonary veins, kinking of the pulmonary vessels (4), or an increase in the volume flow of blood through the lungs in the recumbent position $(5,6)$. The last named factor has been eliminated by the more recent studies of McMichael (7) in patients with congestive failure. The increase in pulmonary congestion by one or more of these factors is believed to induce the dyspnea of recumbency, either by influencing adversely the respiratory exchange (3), by activating reflexes initiated by changes in the parenchyma or blood vessels of the lungs $(3,5,8)$, or by causing increased rigidity of the lungs $(3,9)$.

It has been stated that the appearance of râles or an increase in their number occurs in the recumbent position (10). However, no data bearing on variations in the degree of pulmonary congestion in patients with chronic congestive failure in various positions are available except for McMichael's findings in one case (11). The deviations from the normal in the lung volume and its subdivisions, produced by passive congestion of the lungs, yield a characteristic pattern (9). The lung volume and its subdivisions have therefore been studied in orthopneic patients with chronic congestive failure to learn whether pulmonary congestion increases when orthopneic patients assume the recumbent position.

Although the primary purpose was to investigate the effect of position on pulmonary congestion, data also were obtained on other pulmonary factors which might affect dyspnea of recumbency. Accordingly, the relation between various aspects of respiratory function and orthopnea will be discussed.

The procedure used in the present study is applicable only to patients with mild or moderate orthopnea and therefore conclusions derived from the present experiments may not be wholly applicable to severe orthopnea.

\section{MATERIAL AND METHODS}

Thirteen studies of the effect of changes in posture while in bed on the lung volume and its subdivisions have been made in 12 patients with chronic congestive failure due to rheumatic, arteriosclerotic, or hypertensive heart disease. In 3 subjects (Cases 1, 2, 3), the effect of the application of an abdominal binder was studied with the patient in the upright position. The subjects ranged in age from 18 to 59 years; 6 of them (Cases 2, 6, 8, 9, 10, 11) were men. Nine patients had orthopnea of choice; 3 (Cases 2, 4, 5) had orthopnea of necessity. In 2 instances (Cases 11 and 12), orthopnea was not a complaint at the time of study; Case 11 formerly had had severe orthopnea, but as a consequence of total thyroidectomy, performed 8 years previously, there had been complete and permanent disappearance of this symptom. In 1 patient (Case 10), studies were made while the patient was orthopneic and again after disappearance of that symptom. The method of Christie (12), slightly modified (13), was used throughout. All measurements were made in duplicate, each pair of determinations of functional residual air agreeing within \pm 6.4 per cent. The average deviation was \pm 3.1 per cent. The error of the measurement of the reserve and complemental airs 
was $\pm 20 \mathrm{cc}$. The complemental and reserve airs were measured separately; the 2 were added to obtain the vital capacity. Studies were first made with the patient in the sitting position in bed, with the trunk at an angle of 80 to 90 degrees with the horizontal. Following this, studies were repeated with the patient flat, a 3-inch pillow being placed under the head, or as close to flat as the patient could bear for the 7 minutes required for the test. In 3 subjects, similar studies were then made with the patient in the sitting position, after the application of a snug to moderately tight abdominal binder.

\section{OBSERVATIONS}

The residual air showed no change outside the limits of the error of the method when the subjects changed from the sitting to the recumbent position; the values in the sitting and recumbent positions always agreed within $\pm 115 \mathrm{cc}$., or \pm 5.8 per cent. The averages for all subjects in the sitting and lying positions agreed within $18 \mathrm{cc}$.

The functional residual air was less in the recumbent than in the sitting position in bed in 9 of the 13 experiments, the differences ranging between 120 and $370 \mathrm{cc}$., or 6.1 and 16.5 per cent. In the other 4 instances, the functional residual air was increased in recumbency by 20 to $60 \mathrm{cc}$., or 0.8 to 3.1 per cent; these changes were well within the limits of error of the method. The average decrease in the functional residual air in the recumbent position was 149 cc., or 6.3 per cent, for all the experiments.

TABLE I

Effect of position and abdominal binders on lung volume in congestive failure

\begin{tabular}{|c|c|c|c|c|c|c|c|c|c|c|c|}
\hline Case & $\begin{array}{l}\text { Func- } \\
\text { tional } \\
\text { residual } \\
\text { air }\end{array}$ & $\begin{array}{c}\text { Residual } \\
\text { air }\end{array}$ & $\begin{array}{c}\text { Reserve } \\
\text { air }\end{array}$ & $\begin{array}{c}\text { Com- } \\
\text { ple- } \\
\text { mental } \\
\text { air }\end{array}$ & $\begin{array}{c}\text { Vital } \\
\text { capacity }\end{array}$ & $\begin{array}{c}\text { Total } \\
\text { capacity }\end{array}$ & $\underset{\text { tions }}{\text { Respira- }}$ & $\begin{array}{c}\text { Tidal } \\
\text { air }\end{array}$ & $\begin{array}{l}\text { Respira- } \\
\text { tory } \\
\text { volume }\end{array}$ & \multicolumn{2}{|c|}{ Remarks } \\
\hline & $c c$. & cc. & cc. & cc. & cc. & $c c$. & $\begin{array}{c}\text { per } \\
\text { minute }\end{array}$ & cc. & $\begin{array}{c}\text { liters } \\
\text { per } \\
\text { minute }\end{array}$ & & \\
\hline 1 & $\begin{array}{l}1740 \\
1580 \\
1540\end{array}$ & $\begin{array}{l}1420 \\
1500 \\
1460\end{array}$ & $\begin{array}{r}320 \\
80 \\
80\end{array}$ & $\begin{array}{l}830 \\
830 \\
790\end{array}$ & $\begin{array}{r}1150 \\
910 \\
870\end{array}$ & $\begin{array}{l}2570 \\
2410 \\
2330\end{array}$ & $\begin{array}{l}24 \\
21 \\
26\end{array}$ & $\begin{array}{l}415 \\
400 \\
435\end{array}$ & $\begin{array}{r}10.0 \\
8.4 \\
11.3\end{array}$ & $\begin{array}{l}\text { Sitting } \\
\text { Lying flat } \\
\text { Sitting w. a }\end{array}$ & $\begin{array}{l}\text { Orthopnea } \\
\text { binder }\end{array}$ \\
\hline 2 & $\begin{array}{l}3310 \\
3140 \\
3090\end{array}$ & $\begin{array}{l}2600 \\
2550 \\
2570\end{array}$ & $\begin{array}{l}710 \\
590 \\
520\end{array}$ & $\begin{array}{l}2060 \\
2180 \\
1790\end{array}$ & $\begin{array}{l}2770 \\
2770 \\
2310\end{array}$ & $\begin{array}{l}5370 \\
5320 \\
4880\end{array}$ & $\begin{array}{l}16 \\
20 \\
21\end{array}$ & $\begin{array}{l}595 \\
540 \\
575\end{array}$ & $\begin{array}{r}9.5 \\
10.8 \\
12.1\end{array}$ & $\begin{array}{l}\text { Sitting } \\
\text { Lying } 15^{\circ} \\
\text { Sitting w. a }\end{array}$ & $\begin{array}{l}\text { Orthopnea } \\
\text { binder }\end{array}$ \\
\hline 3 & $\begin{array}{l}2240 \\
1870 \\
1830\end{array}$ & $\begin{array}{l}1440 \\
1320 \\
1290\end{array}$ & $\begin{array}{l}800 \\
560 \\
540\end{array}$ & $\begin{array}{l}1390 \\
1470 \\
1470\end{array}$ & $\begin{array}{l}2190 \\
2030 \\
2010\end{array}$ & $\begin{array}{l}3630 \\
3350 \\
3300\end{array}$ & $\begin{array}{l}14 \\
15 \\
14\end{array}$ & $\begin{array}{l}695 \\
675 \\
735\end{array}$ & $\begin{array}{r}9.7 \\
10.1 \\
10.3\end{array}$ & $\begin{array}{l}\text { Sitting } \\
\text { Lying flat } \\
\text { Sitting w. a }\end{array}$ & $\begin{array}{l}\text { Orthopnea } \\
\text { binder }\end{array}$ \\
\hline 4 & $\begin{array}{l}1790 \\
1670\end{array}$ & $\begin{array}{l}1550 \\
1470\end{array}$ & $\begin{array}{l}240 \\
200\end{array}$ & $\begin{array}{l}1190 \\
1190\end{array}$ & $\begin{array}{l}1430 \\
1390\end{array}$ & $\begin{array}{l}2980 \\
2860\end{array}$ & $\begin{array}{l}22 \\
22\end{array}$ & $\begin{array}{l}400 \\
410\end{array}$ & $\begin{array}{l}8.8 \\
9.0\end{array}$ & $\begin{array}{l}\text { Sitting } \\
\text { Lying } 20^{\circ}\end{array}$ & Orthopnea \\
\hline 5 & $\begin{array}{l}2040 \\
2100\end{array}$ & $\begin{array}{l}1720 \\
1860\end{array}$ & $\begin{array}{l}320 \\
240\end{array}$ & $\begin{array}{l}1940 \\
1940\end{array}$ & $\begin{array}{l}2260 \\
2180\end{array}$ & $\begin{array}{l}3980 \\
4040\end{array}$ & $\begin{array}{l}22 \\
21\end{array}$ & $\begin{array}{l}340 \\
395\end{array}$ & $\begin{array}{l}7.5 \\
8.3\end{array}$ & $\begin{array}{l}\text { Sitting } \\
\text { Lying } 20^{\circ}\end{array}$ & Orthopnea \\
\hline 6 & $\begin{array}{l}2080 \\
1850\end{array}$ & $\begin{array}{l}1680 \\
1660\end{array}$ & $\begin{array}{l}400 \\
190\end{array}$ & $\begin{array}{l}1320 \\
1430\end{array}$ & $\begin{array}{l}1720 \\
1620\end{array}$ & $\begin{array}{l}3400 \\
3280\end{array}$ & $\begin{array}{l}12 \\
12\end{array}$ & $\begin{array}{l}640 \\
640\end{array}$ & $\begin{array}{l}7.7 \\
7.7\end{array}$ & $\begin{array}{l}\text { Sitting } \\
\text { Lying flat }\end{array}$ & Orthopnea \\
\hline 7 & $\begin{array}{l}2320 \\
2340\end{array}$ & $\begin{array}{l}1800 \\
2020\end{array}$ & $\begin{array}{l}520 \\
320\end{array}$ & $\begin{array}{l}1230 \\
1550\end{array}$ & $\begin{array}{l}1750 \\
1870\end{array}$ & $\begin{array}{l}3550 \\
3890\end{array}$ & $\begin{array}{l}27 \\
27\end{array}$ & $\begin{array}{l}395 \\
395\end{array}$ & $\begin{array}{l}10.7 \\
10.7\end{array}$ & $\begin{array}{l}\text { Sitting } \\
\text { Lying flat }\end{array}$ & Orthopnea \\
\hline 8 & $\begin{array}{l}3010 \\
2670\end{array}$ & $\begin{array}{l}2340 \\
2110\end{array}$ & $\begin{array}{l}670 \\
560\end{array}$ & $\begin{array}{l}1150 \\
1230\end{array}$ & $\begin{array}{l}1820 \\
1790\end{array}$ & $\begin{array}{l}4160 \\
3900\end{array}$ & $\begin{array}{l}22 \\
20\end{array}$ & $\begin{array}{l}475 \\
400\end{array}$ & $\begin{array}{r}10.5 \\
8.0\end{array}$ & $\begin{array}{l}\text { Sitting } \\
\text { Lying flat }\end{array}$ & Orthopnea \\
\hline 9 & $\begin{array}{l}2580 \\
2260\end{array}$ & $\begin{array}{l}1870 \\
2060\end{array}$ & $\begin{array}{l}710 \\
200\end{array}$ & $\begin{array}{l}1560 \\
1560\end{array}$ & $\begin{array}{l}2270 \\
1760\end{array}$ & $\begin{array}{l}4140 \\
3820\end{array}$ & $\begin{array}{l}12 \\
20\end{array}$ & $\begin{array}{l}715 \\
475\end{array}$ & $\begin{array}{l}8.6 \\
9.5\end{array}$ & $\begin{array}{l}\text { Sitting } \\
\text { Lying flat }\end{array}$ & Orthopnea \\
\hline 10 & $\begin{array}{l}1980 \\
1760 \\
2340 \\
2070\end{array}$ & $\begin{array}{l}1430 \\
1400 \\
1660 \\
1600\end{array}$ & $\begin{array}{l}550 \\
360 \\
680 \\
410\end{array}$ & $\begin{array}{l}1090 \\
1210 \\
1070 \\
1230\end{array}$ & $\begin{array}{l}1640 \\
1570 \\
1750 \\
1700\end{array}$ & $\begin{array}{l}3070 \\
2970 \\
3410 \\
3300\end{array}$ & $\begin{array}{l}16 \\
17 \\
15 \\
14\end{array}$ & $\begin{array}{l}465 \\
445 \\
415 \\
430\end{array}$ & $\begin{array}{l}7.4 \\
7.6 \\
6.2 \\
5.9\end{array}$ & $\begin{array}{l}\text { Sitting } \\
\text { Lying flat } \\
\text { Sitting } \\
\text { Lying flat }\end{array}$ & $\begin{array}{l}\text { Orthopnea } \\
\text { No orthopnea }\end{array}$ \\
\hline 11 & $\begin{array}{l}1910 \\
1970\end{array}$ & $\begin{array}{l}1710 \\
1870\end{array}$ & $\begin{array}{l}200 \\
100\end{array}$ & $\begin{array}{l}1670 \\
1670\end{array}$ & $\begin{array}{l}1870 \\
1770\end{array}$ & $\begin{array}{l}3580 \\
3640\end{array}$ & $\begin{array}{l}19 \\
17\end{array}$ & $\begin{array}{l}400 \\
370\end{array}$ & $\begin{array}{l}7.8 \\
6.3\end{array}$ & $\begin{array}{l}\text { Sitting } \\
\text { Lying flat }\end{array}$ & No orthopnea \\
\hline 12 & $\begin{array}{l}2390 \\
2410\end{array}$ & $\begin{array}{l}1870 \\
2010\end{array}$ & $\begin{array}{l}520 \\
400\end{array}$ & $\begin{array}{l}1390 \\
1390\end{array}$ & $\begin{array}{l}1910 \\
1790\end{array}$ & $\begin{array}{l}3780 \\
3800\end{array}$ & $\begin{array}{l}16 \\
17\end{array}$ & $\begin{array}{l}455 \\
355\end{array}$ & $\begin{array}{l}7.3 \\
6.0\end{array}$ & $\begin{array}{l}\text { Sitting } \\
\text { Lying flat }\end{array}$ & No orthopnea \\
\hline
\end{tabular}


The reserve air was uniformly less by 40 to 510 cc., or 16.4 to 75.0 per cent in the recumbent as compared to the sitting position. The average difference was $182 \mathrm{cc}$., or 37.8 per cent.

The complemental air was greater in the recumbent than in the sitting position in 7 experiments, the differences ranging between 80 and 320 cc., or 5.6 to 26.0 per cent. In 6 instances, the 2 volumes were identical; in 2 of these instances, the patients were unable to lie flatter than an angle of 20 degrees with the horizontal, and in a third (Case 9), there was abdominal distension due to ascites. The average volume of the complemental air in recumbency was $76 \mathrm{cc}$., or 6.1 per cent, greater than in the sitting position.

The vital capacity was lower in the recumbent than in the sitting position in 11 experiments, the differences ranging between 30 and 510 cc., or 1.6 and 22.5 per cent. In 1 instance, there was no change and in 1 , the vital capacity was $120 \mathrm{cc}$., or 6.9 per cent, larger in recumbency. The average volume of the vital capacity was 106 cc., or 5.9 per cent, smaller in recumbency than in the sitting position.

The total capacity was lower in the recumbent than in the sitting position in 10 experiments, the differences ranging between 20 and $230 \mathrm{cc}$., or 0.5 and 7.7 per cent. In 3 instances; the total capacity was larger in recumbency by 60 to $330 \mathrm{cc}$. The average volume of the total capacity was $83 \mathrm{cc}$., or 2.4 per cent, smaller in recumbency than in the sitting position.

The tidal air was decreased in recumbency, as compared to the sitting position, in 8 instances and increased slightly in 3 ; there was no change in the other 2 subjects. Consistent differences between values for respiratory rate and minute volume in the recumbent and sitting positions were not found.

Effect of abdominal binders. Application of upper abdominal binders in 3 subjects in the sitting position caused no change in residual air. The functional residual and reserve airs decreased approximately to the same degree as when the recumbent position was assumed without the binder (Table I). However, the complemental air did not show changes in the same direction after application of the binder as when the recumbent position was assumed without the binder. The measurements derived from the complemental air, i.e., the vital and total capacities, were lower after application of the binder than in recumbency without the binder. In all instances, application of the binder caused increases in respiratory minute volume as compared to the values in the upright position without binders; the patients complained of dyspnea in the sitting position after the binder was applied.

\section{DISCUSSION}

McMichael and McGibbon (14), in a recent study, showed that when normal subjects change from the sitting to the lying position, the characteristic findings are (1) little or no change in residual air, (2) a decrease in functional residual air due entirely or almost entirely to (3) a decrease in reserve air, (4) an increase in complemental air, (5) a small decrease in vital capacity, and ( 6$)$ a small decrease in total capacity. These conclusions are in agreement with those of earlier authors (14) as well as our own (Figure 1). In cardiac decompensation, according to Christie and Meakins (9), when the lungs become congested, the vital and total capacities are greatly reduced because of a marked decrease in the complemental and reserve airs. The residual and functional residual airs are markedly increased, relative to the total pulmonary capacity. The fact that the ratio of functional residual to total capacity increases with pulmonary congestion has been used in the present study as a measure of whether or not the degree of congestion in orthopneic cardiac patients varies with position.

It is clear that if an increase in the ratio of functional residual air to total capacity occurs, with a marked decrease in the complemental air, when orthopneic patients change from the sitting to the recumbent position in bed, it would be valid to conclude that the occurrence or exaggeration of respiratory discomfort in recumbency is associated with an increase in pulmonary congestion. The results of the present study on patients with mild or moderate orthopnea do not support such a conclusion. The changes in the lung volume and its subdivisions, which occurred in our patients with orthopnea on change of position, were similar to those which occur in normal subjects under comparable circumstances (14). In the 


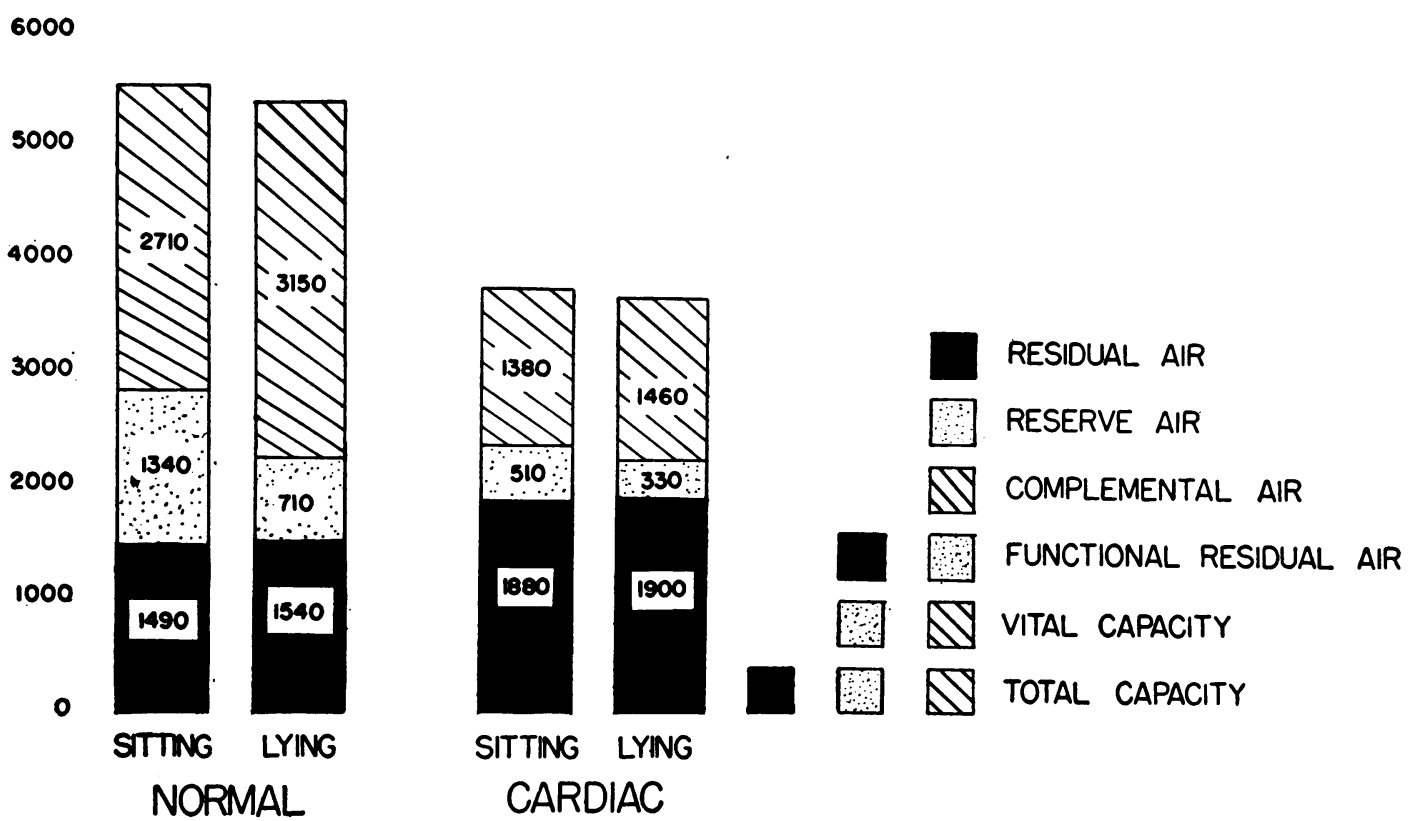

Fig. 1. Effect of Position on the Subdivisions of the Lung Volume in Normal and Cardiac SubJeCts

sitting position in bed, all patients showed the usual changes resulting from congestive failure; however, when the recumbent position was assumed, there was no further decrease in complemental air or increase in the ratio of functional residual air to total capacity (Table II). Indeed, in 10 of the 13 experiments, there was a definite decrease in this ratio, while in the other 3 , the increases were insignificant. Furthermore, the changes observed in recumbency in the decompensated patients without orthopnea (Cases 11 and 12) were the same as those with orthopnea (Cases 1 to 10); similarly, in 1 patient (Case 10),

TABLE II

Functional residual air/total capacity $\times 100$

\begin{tabular}{ccc}
\hline \hline Case & Sitting & Lying \\
\hline 1 & 67.7 & 65.6 \\
2 & 61.6 & 59.0 \\
3 & 61.7 & 55.8 \\
4 & 60.1 & 58.4 \\
5 & 51.2 & 52.0 \\
6 & 61.2 & 56.4 \\
7 & 65.4 & 60.3 \\
8 & 72.4 & 68.4 \\
9 & 62.3 & 59.2 \\
10 & 64.5 & 59.3 \\
& 68.6 & 62.7 \\
11 & 53.4 & 54.1 \\
12 & 63.3 & 64.1 \\
\hline
\end{tabular}

variations in the subdivisions of the lung volume, due to changing position, were qualitatively the same when orthopnea was present as when it was absent. ${ }^{1}$

The vital and total capacities decreased slightly when the subjects of the present study changed from the sitting to the lying position; this was consequent to the fact that the complemental air failed to increase as much as the reserve air decreased. Similar changes occur in normal subjects and have been ascribed, without evidence, to an increase in the amount of blood in the lungs in recumbency (14). However, in view of the fact that the ratio of functional residual to total lung volume decreases in recumbency, it is quite

1 McMichael (11) reported a marked decrease in lung volume in one orthopneic patient on assuming the lying position; this was associated with decreases in reserve air and vital capacity and an increase in complemental air, similar in magnitude to those observed by us in the present study. McMichael's finding of a decrease of 50 per cent in the residual air in recumbency suggests some gross error in its measurement, as does the fact that the ratio of functional residual air to total capacity in his patient, which was definitely abnormal in the sitting position, became quite normal in recumbency. Accordingly, his conclusion that an increase in congestion occurred in recumbency in that patient cannot be accepted. 
unlikely that such an increase in pulmonary blood volume occurs.

It is to be noted that the results of the present study show only that no increase in pulmonary congestion occurs when cardiac patients, sitting in bed, lie down. No attempt was made to study the changes in pulmonary dynamics following prolonged still-standing, or sitting with legs down by the patient, or the application of tourniquets or venesection by the physician. All these procedures tend to ameliorate orthopnea and all must be associated with the withdrawal of blood from the lungs. Pulmonary congestion must therefore be responsible, at least in part, for the occurrence of orthopnea in cardiac patients. Passive congestion makes the lungs abnormally rigid and raises the intrapleural pressure (9). The manner in which these changes favor the occurrence of orthopnea is discussed below.

Although no increase in pulmonary congestion in recumbency was demonstrated in the present study, it is not to be concluded that changes in pulmonary dynamics in that position are unrelated to the genesis of orthopnea. The decrease in reserve air and increase in complemental air in recumbency in normal subjects were shown by McMichael and McGibbon (14) to be caused by a cephalad shift of the diaphragm, due presumably to the pressure of the abdominal viscera. The occurrence of similar changes in recumbency in congestive failure also appears to be due to a shift in the diaphragm. Thus, in the present study, forcing the diaphragm upward by application of an upper abdominal binder in the sitting position in 3 subjects caused approximately the same decrease in reserve air, without change in the residual air, as did assuming the recumbent position. The increase in complemental air which occurs on lying down could not always be reproduced by the application of the upper abdominal binder which, in contrast to the abdominal viscera, is inelastic and prevents full expansion of the lungs. It is worthy of note that the application of the abdominal binder made the patients, normally comfortable when sitting, dyspneic in that position and increased their respiratory minute volumes. It is to be concluded, therefore, that a cephalad shift of the diaphragm, which occurs in recumbency and is due to pressure of the abdominal viscera, is responsible in part for orthopnea. Other authors (9) have shown that the shift in the level of the diaphragm in recumbency results in a decrease in the volume of the functional residual air and an associated lessening of the negativity of the intrapleural pressure in normal subjects. Similarly, the decrease in functional residual air in recumbency, here shown to occur in orthopneic patients, is also associated with a decrease in the negativity of the intrapleural pressure in that position (15). The intrapleural pressure in patients with congestive failure is, however, less negative than normal and may be positive during expiration, even in the sitting position (9). Further changes in this direction cause increased respiratory embarrassment and inefficiency (9). This is probably the cause of the smaller tidal volumes in recumbency, as compared to the sitting position, in a majority of orthopneic cardiac patients noted by Calhoun et al. (16) and also by us in the present study. Decreased tidal air volumes in recumbency should result in less complete aeration of blood passing through the lungs. On the other hand, the relatively small decreases in lung volume and its subdivisions, which occur when orthopneic patients lie down, indicate that decrease of space available for breathing does not cause orthopnea, as Christie and Beams (17) and Calhoun et al. (16) believe.

When normal subjects change from the sitting to the lying position, respiration is slowed and the tidal air increases (18). If this increase in tidal air cannot occur, even normal subjects will develop evidences of anoxemia (18). It is therefore not surprising that increased dyspnea occurs in many patients with congestive failure in recumbency, since the increased rigidity of their lungs (9) makes it difficult to augment the tidal air, and the aforementioned respiratory ineffciency in recumbency may actually result in a decrease in tidal volume. Lower levels of arterial blood oxygen saturation in the recumbent position, as compared to the sitting position, have been reported by Calhoun et al. (16) in patients with congestive failure. These authors reported arterial blood oxygen saturations of 88.6 to 94.0 per cent in the recumbent position in 7 orthopneic cardiac patients, without associated pulmonary disease; these increased to 93.5 to 98.6 per cent in the upright position in 6 of the 7 cases, the in- 


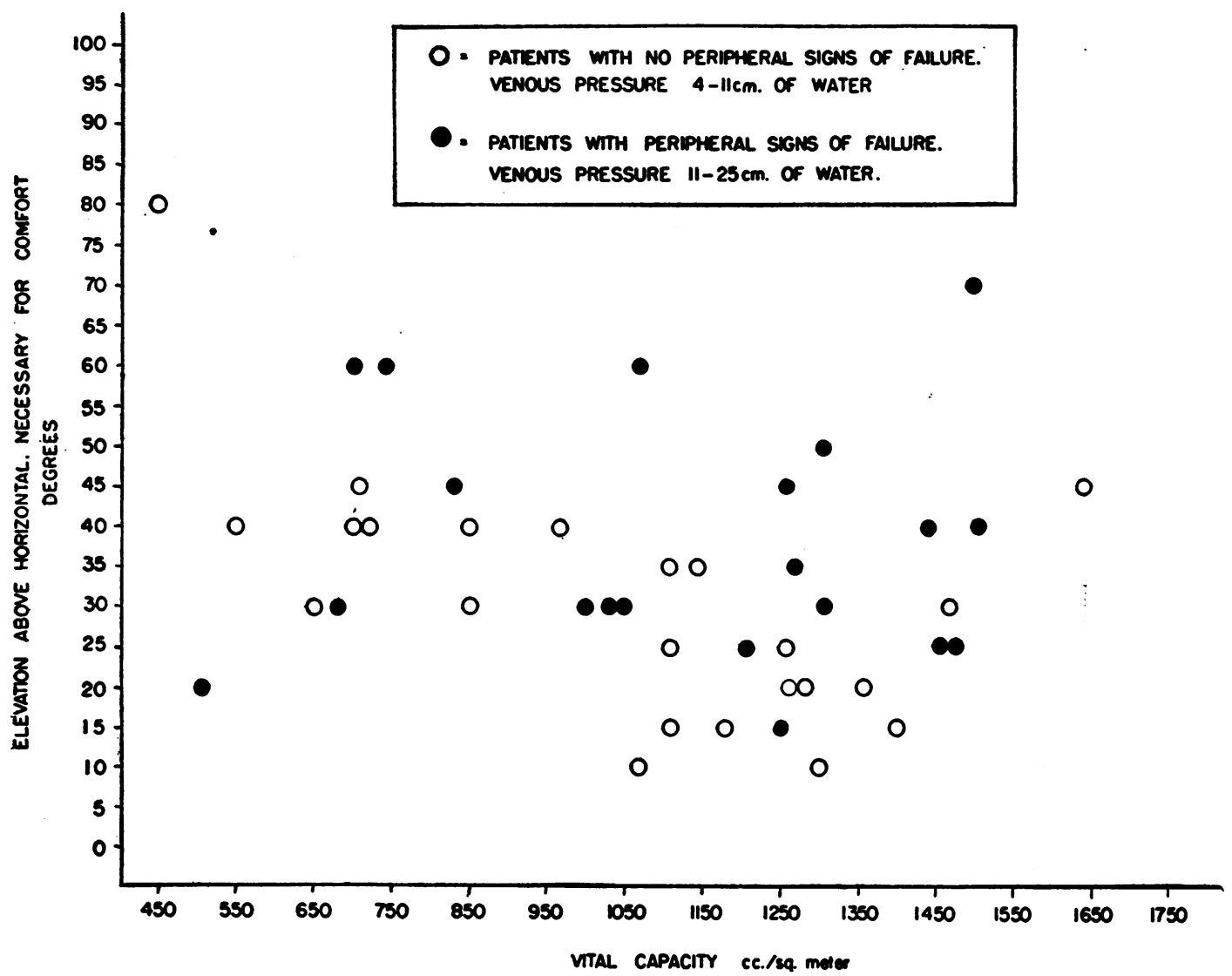

Fig. 2. Relation Between Vital Capacity and Severity of Orthopnea in Patients with Normal and Elevated Venous Pressures (Data of Robb and Weiss (24))

creases ranging between 0.6 and 8.1 per cent. In some instances, a considerable rise in respiratory rate occurs as a consequence of increased anoxia in recumbency and this increase in respiratory activity may increase the severity of dyspnea. In addition to all these factors, there appears to be a greater ease of respiratory movement in the upright position which contributes to the genesis of orthopnea.

A more positive intrapleural pressure also causes an increase in peripheral venous pressure and thereby in spinal pressure as well. The role of elevated venous $(19,20)$ and spinal fluid (21 to 23) pressures in the genesis of orthopnea has been discussed by other authors.

Recumbency causes qualitatively the same changes in the lungs in normal subjects and in patients with congestive failure; indeed, the changes in normal subjects are considerably greater than in patients with congestive failure
(Figure 1). Nevertheless, orthopnea does not occur in the former and is frequently observed in the latter. Neither the nature of the postural changes in pulmonary dynamics nor their magnitude appears to be responsible for orthopnea in patients with pulmonary congestion; rather, it is the state of respiration and circulation at the time these changes occur that is important in the genesis of orthopnea. The occurrence of orthopnea, although influenced profoundly by the above discussed factors, is conditioned by fundamental changes due to congestive failure; these are (a) increased venous and spinal fluid pressures and (b) increased rigidity of the lungs and lessened negativity of the intrapleural pressure. It is apparent, therefore, that more marked myocardial insufficiency, or an exaggeration of $(a)$ or $(b)$ not due to increased failure of the heart, must result in more severe orthopnea as long as the patient remains conscious. Conversely, the relief of 


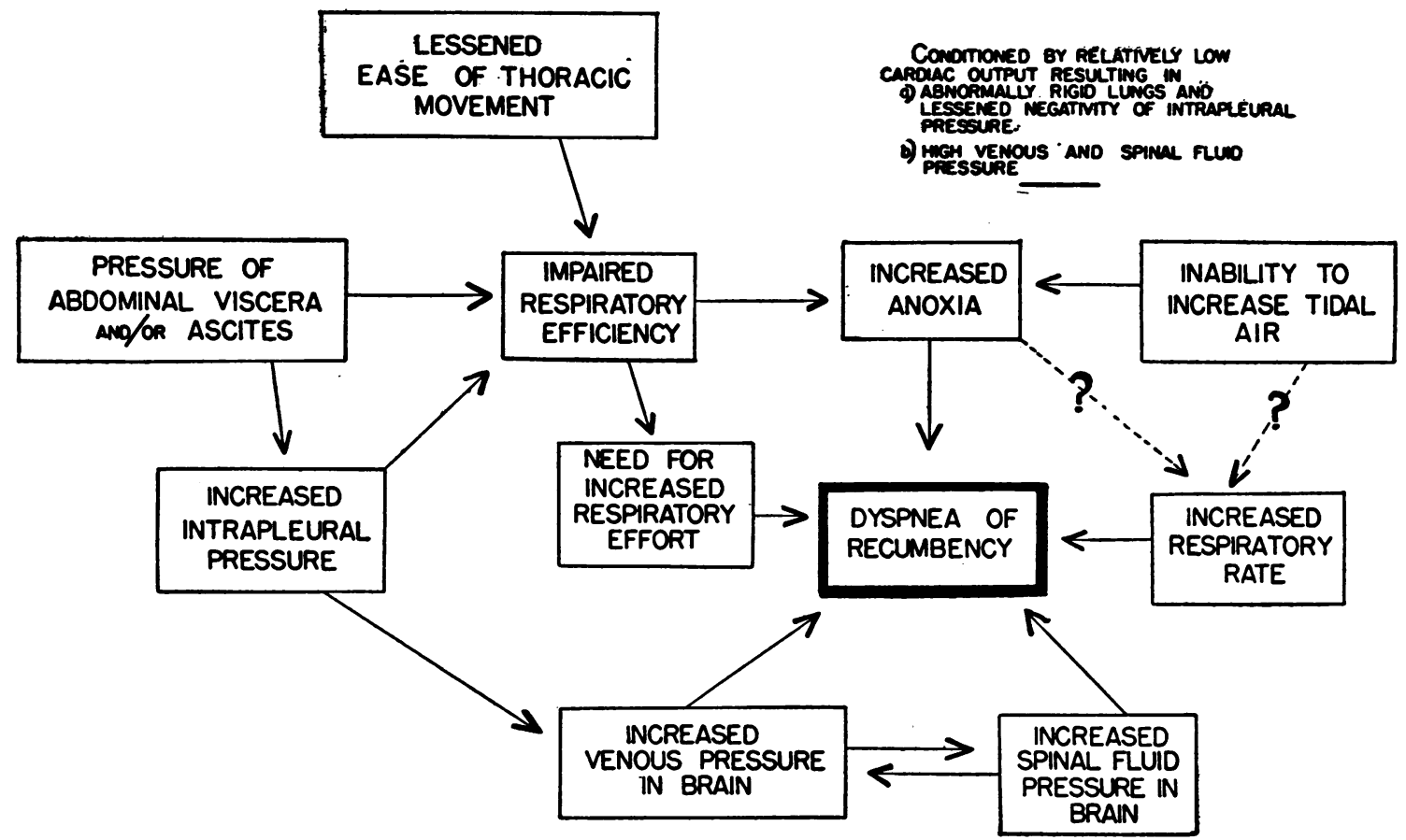

Fig. 3. Some of the Factors Which Influence the Occurrence of Orthopnea in Patients with Chronic Congestive Failure

orthopnea may be a consequence of improved cardiac function or it may occur as a result of lowered venous or spinal fluid pressures or lessened rigidity of the lungs, independent of changes in cardiac function.

This discussion is limited to consideration of the pulmonary factors involved in the genesis of orthopnea and has not touched on the changes in cerebral vascular dynamics which may also cause this symptom, except to note that the intracranial factors are influenced to some extent by the changes in the intrapleural pressure. A more extensive discussion of the relation between intracerebral blood flow and orthopnea will be presented elsewhere. It should be pointed out, however, that the data of other authors show that even in patients with low vital capacities factors operating outside of the lungs are significant. The data of Robb and Weiss (24) show that, for a given vital capacity volume per unit of body surface, patients with peripheral signs of congestive failure, including elevation of the venous pressure, generally exhibit more severe orthopnea than patients with no peripheral signs of congestive fail- ure and normal venous pressure (Figure 2). A valid general conclusion is that orthopnea in congestive failure is due to the summation of the effects of a multiplicity of complexly interrelated factors; the complexity of the interrelationships between the pulmonary factors alone is illustrated graphically in Figure 3. The importance of each factor in the genesis of orthopnea probably varies from patient to patient.

\section{SUMMARY AND CONCLUSIONS}

1. Studies of the subdivisions of the lung volume were made in 12 patients with congestive failure in the sitting and recumbent positions.

2. No increase in the degree of pulmonary congestion was demonstrated in recumbency in orthopneic patients.

3. A cephalad shift of the diaphragm occurs in recumbency; this causes changes in respiration and circulation which tend to increase dyspnea.

4. The complexity of interrelated factors which are related to the genesis of the orthopnea of congestive failure is discussed. 


\section{BIBLIOGRAPHY}

1. Hill, L., The influence of the force of gravity on the circulation of the blood. J. Physiol., 1895, 18, 15.

2. Reid, W. D., Engorgement of the pulmonary veins by extension of cardiac enlargement posteriorly. Relation to postural dyspnea in cardiac patients. New Eng. J. Med., 1940, 222, 627.

3. Dock, W., The anatomical and hydrostatic basis of orthopnea and of right hydrothorax in cardiac failure. Am. Heart J., 1935, 10, 1047.

4. Rubow, V., Die kardiale Dyspnoe. Ergebn. d. inn. Med. u. Kinderh., 1909, 3, 73.

5. Field, H., Jr., and Bock, A. V., Orthopnea and the effect of posture upon the rate of blood flow. J. Clin. Invest., 1925, $2,67$.

6. Nielsen, H. E., Der Einfluss der Koerperstellung auf das Herzminutenvolumen. Acta med. Scandinav., 1936, 90, 456.

7. McMichael, J., The output of the heart in congestive failure. Quart. J. Med., 1938, 7, 331.

8. Christie, R. V., Dyspnoea : A review. Quart. J. Med., 1938, 7, 421.

9. Christie, R. V., and Meakins, J. C., The intrapleural pressure in congestive heart failure and its clinical significance. J. Clin. Invest., 1934, 13, 323.

10. Digilio, V. A., and Pescatore, J. A., An early sign of left-sided heart failure. Internat. Clin., 1940, 2, 86.

11. McMichael, J., The significance of cardiac venous congestion. Tr. Med.-Chir. Soc. Edinburgh, 193738, 117, 161.

12. Christie, R. V., The lung volume and its subdivisions. I. Methods of measurement. J. Clin. Invest., 1932, $11,1099$.

13. Iglauer, A., and Altschule, M. D., The effect of arterial and venous constriction induced by paredrine on the lung capacity and its subdivisions. Am. J. M. Sc., 1941, 201, 664.
14. McMichael, J., and McGibbon, J. P., Postural changes in lung volume. Clin. Sc., 1939, 4, 175.

15. Prinzmetal, M., and Kountz, W. B., Intrapleural pressure in health and disease and its influence on body function. Medicine, 1935, 14, 457.

16. Calhoun, J. A., et al., Studies in congestive heart failure. XIV. Orthopnea: Its relation to ventilation, vital capacity, oxygen saturation and acid-base condition of arterial and jugular blood. J. Clin. Invest., 1931, 10, 833.

17. Christie, C. D., and Beams, A. J., Orthopnea. Arch. Int. Med., 1923, 31, 85.

18. Haldane, J. S., Meakins, J. C., and Priestley, J. G., The effects of shallow breathing. J. Physiol., 1919, $52,433$.

19. Ernstene, A. C., and Blumgart, H. L., Orthopnea. Its relation to increased venous pressure of myocardial failure. Arch. Int. Med., 1930, 45, 593.

20. Altschule, M. D., and Blumgart, H. L., The circulatory dynamics in tricuspid stenosis. Am. Heart J., 1937, 13, 589.

21. Harrison, W. G., Jr., The cisternal pressure in congestive heart failure and its bearing on orthopnea. J. Clin. Invest., 1933, 12, 1075.

22. Harrison, W. G., Jr., Cerebrospinal fluid pressure and venous pressure in cardiac failure and the effect of spinal drainage in the treatment of cardiac decompensation. Arch. Int. Med., 1934, 53, 782.

23. Robertson, H. F., and Fetter, F., The effect of venesection on arterial, spinal fluid, and venous pressures with especial reference to failure of the left and right heart. J. Clin. Invest., 1935, 14, 305.

24. Robb, G. P., and Weiss, S., The velocity of pulmonary and peripheral venous blood flow and related aspects of the circulation in cardiovascular disease. Their relation to clinical types of circulatory failure. Am. Heart J., 1934, 9, 742. 